\title{
Ascribing patients a passive role: Conversation analysis of practice nurses' and patients' goal setting and action planning talk
}

Citation for published version (APA):

Lenzen, S. A., Stommel, W., Daniels, R., van Bokhoven, M. A., van der Weijden, T., \& Beurskens, A. (2018). Ascribing patients a passive role: Conversation analysis of practice nurses' and patients' goal setting and action planning talk. Research in Nursing \& Health, 41(4), 389-397. https://doi.org/10.1002/nur.21883

Document status and date:

Published: 01/08/2018

DOI:

10.1002/nur.21883

Document Version:

Publisher's PDF, also known as Version of record

Document license:

Taverne

Please check the document version of this publication:

- A submitted manuscript is the version of the article upon submission and before peer-review. There can be important differences between the submitted version and the official published version of record.

People interested in the research are advised to contact the author for the final version of the publication, or visit the DOI to the publisher's website.

- The final author version and the galley proof are versions of the publication after peer review.

- The final published version features the final layout of the paper including the volume, issue and page numbers.

Link to publication

\footnotetext{
General rights rights.

- You may freely distribute the URL identifying the publication in the public portal. please follow below link for the End User Agreement:

www.umlib.nl/taverne-license

Take down policy

If you believe that this document breaches copyright please contact us at:

repository@maastrichtuniversity.nl

providing details and we will investigate your claim.
}

Copyright and moral rights for the publications made accessible in the public portal are retained by the authors and/or other copyright owners and it is a condition of accessing publications that users recognise and abide by the legal requirements associated with these

- Users may download and print one copy of any publication from the public portal for the purpose of private study or research.

- You may not further distribute the material or use it for any profit-making activity or commercial gain

If the publication is distributed under the terms of Article 25fa of the Dutch Copyright Act, indicated by the "Taverne" license above, 


\title{
Ascribing patients a passive role: Conversation analysis of practice nurses' and patients' goal setting and action planning talk
}

\author{
Stephanie A. Lenzen ${ }^{1,2}$ (D) | Wyke Stommel ${ }^{3}$ | Ramon Daniëls ${ }^{1}$ | \\ Marloes A. van Bokhoven ${ }^{2}$ । Trudy van der Weijden ${ }^{2}$ । Anna Beurskens ${ }^{1,2}$
}

1 Research Centre for Autonomy and Participation for People with a Chronic Illness, Zuyd University of Applied Sciences, Heerlen, the Netherlands

2 Department of Family Medicine, CAPHRI School for Public Health and Primary Care, Maastricht University, Maastricht, the Netherlands

${ }^{3}$ Centre for Language Studies, Radboud University, Nijmegen, the Netherlands

\section{Correspondence}

Stephanie Lenzen, Research Centre for Autonomy and Participation for People with a Chronic Illness, Zuyd University of Applied Sciences, Nieuw Eyckholt 300, 6419 DJ

Heerlen, the Netherlandsa

Email: stephanie.lenzen@zuyd.nl

Funding information

Stichting Innovatie Alliantie, Grant number: (PRO-3-36); Zuyd University of Applied

Sciences, Heerlen, the Netherlands
Within primary care, nurses are expected to set goals and make action plans with patients. However, little information is available on how this is done. The aim of this study is to gain insight into how nurses set goals and action plans with patients. Data were collected from three practice nurses working in elderly care and five patients in the Netherlands. Practice nurse is the term for the home care registered nurse in the Netherlands. Five home visits for which goal setting and action planning were the main agreed-upon objectives, were video-recorded and transcribed. We found that explicit goal setting was not observable. However, in 16 episodes, action plans were discussed. Action planning was always initiated by the nurse and was oriented toward offering professional help or assistance in order to solve the patient's problems. In response, patients tended to resist the proposed solutions, with the result that action planning was abandoned. By the nurse proposing professional help, patients were positioned as passive rather than active agents. Our results contribute to the understanding of how nurses' communicative behavior influences the extent to which patients feel encouraged to actively participate in goal setting/action planning.

\section{KEYWORDS}

action planning, conversation analysis, goal setting, home care nurse, self-management support

\section{1 | INTRODUCTION}

The increasing number of people living with one or more chronic conditions and the increasing number of elderly people with complex health care demands require an effort to develop effective selfmanagement interventions (Embrey, 2006). Self-management is defined as "the degree to which a patient with a chronic condition is able and willing to control his or her daily life" (Wagner et al., 2005). Self-management is important for improving health and well-being and reducing the economic burden of healthcare on society (Bodenheimer, MacGregor, \& Sharifi, 2005; Embrey, 2006).
Health care professionals' support of self-management includes collaborative goal setting and action planning (Bodenheimer \& Handley, 2009). Goal setting is a process of mutual agreement between professionals and patients concerning patients' healthrelated goals, and is thought to increase patients' motivation, confidence, and understanding (Bodenheimer \& Handley, 2009). Action planning is defined as agreeing on a course of action to achieve the goal, addressing details such as what, when, where, and how often (Bodenheimer \& Handley, 2009; Lorig, 2006). During goal setting and action planning, the patient and the professional collaborate, make shared decisions and constantly reflect on these 
decisions (Lenzen, Daniëls, van Bokhoven, van der Weijden, \& Beurskens, 2015; Scobbie, Dixon, \& Wyke, 2011). First, the patient's perspective, needs, and problems are explored (Bodenheimer \& Grumbach, 2007). Subsequently, achievable goals that are important to the patient should be identified. Then, action plans are formulated to achieve those goals (Oettingen \& Gollwitzer, 2010; Scobbie et al., 2011).

Although goal setting and action planning are core components of self-management, qualitative exploratory research shows that they rarely occur in routine care due to communicational difficulties (Kennedy et al., 2014; Schulman-Green, Naik, Bradley, McCorkle, \& Bogardus, 2006). However, it remains unclear what these communicational difficulties are. The few conversation analytic studies that have examined these difficulties in detail have found that goals and action plans are often proposed by professionals, but that patients often show resistance toward these goals and action plans (Parry, 2004; Schoeb, 2009). Conversation analytic research shows that professionals struggle to elicit patients' views and achieve mutual understanding and agreement concerning goals and action plans (Parry, 2004). It is indicated that these struggles can partially be explained by the asymmetry of power between the professional and the patient in health care, leading to patient's reluctance to take an active role in decision making (Heath, 1992; Parry, 2004).

In primary care, practice nurses can play an important role in goal setting and action planning. Practice nurse is the term for the home care registered nurse in the Netherlands. Practice nurses regularly consult with patients with chronic conditions and elderly people, and they frequently work alongside family physicians, carrying out tasks related to chronic disease management (Laurent et al., 2005; Van Dijk-de Vries, 2015; Willard-Grace et al., 2015). Qualitative studies focusing on goal setting practices conclude that practice nurses have difficulty exploring patients' experiences, translating needs, and problems into goals, and making shared decisions about goals and actions (MacDonald, Rogers, Blakeman, \& Bower, 2008; van Dillen et al., 2015). This seems to be especially true for goal setting with elderly patients, as elderly people often suffer from multimorbidity and have multi-dimensional goals, which do not focus only on medical aspects, but also on well-being and functioning (Vermunt, Harmsen, Westert, Rikkert, \& Faber, 2017).

Still, there are no studies available that thoroughly explore how goal setting and action planning are actually accomplished by nurses in primary elderly care, what the difficulties are and what causes them. It is therefore worth examining practice nurses' and patients' goal setting and action planning practices in depth to gain greater insights into the challenges. The aim of this article is to examine how practice nurses working in primary elderly care set goals and formulate action plans with their elderly patients.

\section{2 | METHODS}

\section{1 | Design and setting}

The study comprises an exploratory, observational study of goal setting and action planning consultations between practice nurses working in primary elderly care $(n=3)$ and their elderly patients $(n=5)$, in the Netherlands. Working in family medicine practices, elderly care practice nurses regularly make home visits to patients who are experiencing problems in their everyday life due to chronic conditions or other age-related impairments. During these home visits, practice nurses and patients are expected to set goals and make plans that are relevant to the patient and his/her environment.

\section{2 | Ethical considerations}

All participants (three nurses, five patients and two informal caregivers) gave written informed consent for recording the home visits. All names in the transcripts have been replaced with pseudonyms. The study was approved by the Medical Ethics Committee of the Atrium Medical Center, Heerlen, the Netherlands.

\section{3 | Sample, data collection, and procedures}

Three practice nurses working with elderly people were recruited from our professional network (convenience sample). The practice nurses were aged between 35 and 50 years and their work experience ranged from 10 to 20 years. Nurses invited us to home visits/consultation in which they planned to discuss goals and agree on action plans with the patient. Using a camera or audio recorder (depending on patient approval), five total home visits (two nurses invited us to two home visits each, and one nurse invited us to one home visit) were observed and recorded.

The five patients were between 75 and 85 years old and lived independently at home. Patients had been diagnosed with several chronic conditions and/or experienced problems taking care of themselves (see Table 1. Patient characteristics). During two home visits, a family member was also present.

\section{4 | Data analysis}

The theoretical and analytical framework of conversation analysis (CA) was used to analyse the data (Atkinson \& Heritage, 1984; Peräkylä, 2004; Ten Have, 2007). CA examines naturally occurring social interactions and aims to identify communicational patterns and describe specific interactional consequences which follow from a given verbal practice (Peräkylä, 1997). Any utterance is considered to be a social action; what one participant says and does is generated by and dependent upon what the other had said and done (Heath, 1986; Robinson, 1998). Moreover, CA researchers look at various layers or dimensions of interactions, including, turn-taking, sequence organization, turn design, repair, and overall structural organization (Heritage \& Clayman, 2010). CA transcripts are highly detailed (timing of utterances, sound production, intonation etc.), in order to be able to thoroughly examine the characteristics of communication and to illustrate that minor aspects of wording and phrasing can have consequences for the interaction (Drew, Chatwin, \& Collins, 2001). The analysis is iterative, alternating between data and previous studies of spoken interaction in order to find regularities (Ten Have, 2007). 
TABLE 1 Patient characteristics

\begin{tabular}{|c|c|c|c|c|c|}
\hline Code & Gender & Age & Education level & Living situation & Reason for the home visit \\
\hline 1 & Man & 80 & Tertiary education & Lives alone & $\begin{array}{l}\text { The patient experiences a decline in mobility, } \\
\text { leading to problems in everyday activities, since } \\
\text { his wife died ( } 12 \text { months earlier) he feels lonely }\end{array}$ \\
\hline 2 & Woman & 75 & Tertiary education & Lives alone & $\begin{array}{l}\text { The patient suffers from diabetes and recently } \\
\text { got a stoma because of an inflammatory bowel } \\
\text { disease, she experiences problems in her house } \\
\text { holding and sometimes feels lonely }\end{array}$ \\
\hline 3 & Woman & 82 & Primary education & Lives alone & $\begin{array}{l}\text { The patient suffers from diabetes and COPD, } \\
\text { leading to a decline in mobility and problems in } \\
\text { self-care activities (e.g. preparing food) }\end{array}$ \\
\hline 4 & Man & 85 & Secondary education & Lives together with his son & $\begin{array}{l}\text { The patient suffers from diabetes, hearing problems } \\
\text { and insomnia, because of a decline in mobility he is } \\
\text { not able to go outside anymore, which makes him } \\
\text { feel frustrated }\end{array}$ \\
\hline 5 & Woman & 81 & Primary education & Lives alone & $\begin{array}{l}\text { The patient suffers from COPD and thereby } \\
\text { experiences problems in living at home independently } \\
\text { (e.g. going up the stairs), she plans to move to a nursing home }\end{array}$ \\
\hline
\end{tabular}

From the data (five home-visits) we selected all episodes of goal setting and/or action planning. An episode was defined as goal setting when the practice nurse and the patient agreed on a health-related goal (i.e., what does the patient want to change or achieve?). An episode was defined as action planning when the practice nurse and the patient collaboratively agreed on a course of action to reach the goal(s), addressing details such as what, when, where, and how often the action will occur. We found 16 episodes mainly related to the "what"- in other words, possible solutions to the patient's problems were discussed during these episodes. We analysed each episode line by line, focusing on how the action was proposed/suggested and subsequently responded to.

The episodes were transcribed using CA conventions (see Table 2 for transcription conventions) (Jefferson, 2004). The English translations, made by the first and second author of this article, are as close to the Dutch original as possible. The translation was done word for word. For the ease of reading, the original Dutch text was excluded in the extracts presented in this article. The extracts including both the original Dutch text and the English translation can be found in the supplementary data.

\section{3 | RESULTS}

In the 16 episodes in which possible actions were discussed, we found recurring communication patterns. The extracts we present are examples of the patterns we identified.

Characteristic of all episodes was that the actions involved possible solutions to patients' problems rather than actions oriented toward achieving a goal. Problems, rather than goals, were articulated as the basis for an action (e.g., to use a service). Moreover, the discussion of solutions was always initiated by the practice nurses (PN) and consisted of offers, proposals or the advice to seek professional assistance services (e.g., transport services, psychological support). Patients were rarely asked about their own ideas for actions or solutions. Thereby, the PNs cast patients as passive entities with regard to the problem in question; patients tended to submit to being treated as passive. From the passive position, they declined the solutions offered by the PNs without proposing alternative solutions. As PNs rarely explored the reasons for patients' resistance, the problem discussions were closed with no action plan agreed upon. However, in one case, the patient was asked what he could do; the PN approached him as a person who is capable of actively engaging in solving his problem.

\subsection{The passive patient}

The first extract shows how the PN's initiation of a discussion concerning solutions to the patient's loneliness is oriented toward offering assistance. The consultation involves patient code 1 . The PN and the patient have known each other for several years. During the previous home visit ( 3 months earlier) the $\mathrm{PN}$ and the patient discussed the patient's main problem: loneliness. Since the death of his wife (12 months earlier) the patient had been feeling increasingly lonely. He expressed interest in meeting new people, but is hampered by a decline in mobility, as well as by doubts about how to approach people. During the previous home visit the patient and the PN agreed to set goals and make action plans for this "problem." Extract 1 shows how the PN initiates a discussion about possible solutions. $\mathrm{P}$ denotes the patient, and $\mathrm{PN}$ denotes the practice nurse.

\section{Extract 1}

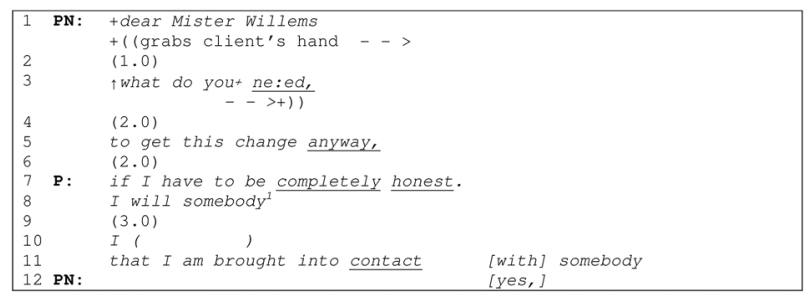


TABLE 2 Transcription conventions

\begin{tabular}{|c|c|}
\hline Symbol & Explanation \\
\hline$(0.0)$ & Indicates elapsed time in silence in tenths of a second \\
\hline (.) & Indicates a gap of no more than one-tenth of a second \\
\hline WORD & Indicates especially loud sounds relative to surrounding talk \\
\hline : & $\begin{array}{l}\text { Indicates prolonging of the immediately prior sound, length of } \\
\text { row of colons indicates length of prolongation }\end{array}$ \\
\hline . & Indicates a gradual falling intonation \\
\hline ] & Indicates the onset of overlapping talk \\
\hline ] & Indicates the end of overlapping talk \\
\hline (word) & Indicates possible hearing of what was said \\
\hline$=$ & Indicates the vocalization very closely follows that which went before \\
\hline ((italic text)) & Brief description of body movement or tone of voice \\
\hline $\begin{array}{l}+--> \\
--->+\end{array}$ & $\begin{array}{l}\text { Indicates the beginning and end of body movement } \\
\text { (used to show body movement lasting several lines) }\end{array}$ \\
\hline
\end{tabular}

In a rather intimate way (addressing patient's name, holding the hand), the PN asks the patient what he needs, in response to the patient's report that the self-help group was not helpful (lines 1-5). She stresses the question's relevance by emphasizing and extending the verb "need." When the patient pauses, she expands the turn with a focus on achieving a "change" (line 5), that the self-help group was unable to provide. Thereby, she emphasizes the relevance of a solution. The modality of the question "need" (line 3) and the verb "get" (line 5) put the patient in a passive position, implying he should be helped rather than help himself. The patient aligns with being positioned as passive, using a passive construction ("that I am brought into contact with somebody," line 11). The patient's response exhibits in various ways that what he wants is a delicate issue to ask ("if I have to be completely honest", line 7 (Edwards \& Fasulo, 2006) and the self-repair in lines 8-10). However, although the delicacy may indicate doubts concerning the appropriateness of what the patient needs (Ahmad Al-Harahsheh, 2015), he settles with the PN's orientation to his state of needing assistance. Hence, the patient's passive role is collaboratively constructed.

The next extract shows another example of the collaborative achievement of the patient's passive role. In this case, the orientation to needing help is particularly strong in the patient's uptake of the PN's suggestion. The PN visits the patient (code 2) for the first time. The family physician asked the nurse to visit the patient as the patient recently received a stoma, because the family physician thought that the patient was having problems handling the stoma. Prior to this exchange, the patient just explained that she sometimes feels distressed/uncomfortable about the stoma. At this point, the PN enquires whether she's ever thought about getting help.

\section{Extract 2}

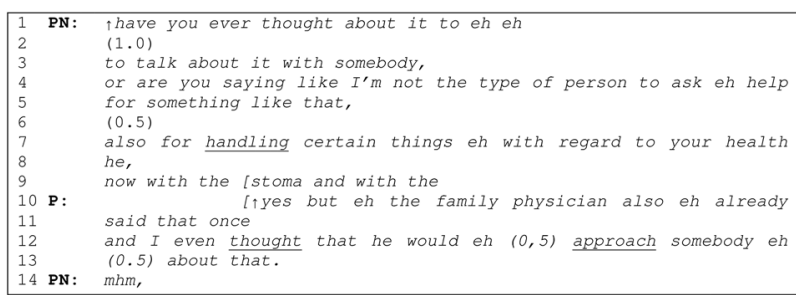

Rather than exploring a goal, the PN enquires whether the patient has ever considered a specific action: seeking psychological help (lines 1-3). This question indirectly suggests that seeking help would be a solution. The action proposal requires some active participation from the patient ("seek"), but it is passive in the sense that it would involve accepting a service. In the absence of agreement from the patient, the question is followed by an alternative question ("or," line 4), which reverses the preference structure of the initial question. This means that alignment with the question would be a decline of the suggestion to seek help ("not the type of person to ask help for something like that"). The patient does not respond immediately (line 6), which leads the $\mathrm{PN}$ to expand her first question by giving reasons for her suggestion to seek psychological help (lines 7-9). In response, the patient explains the family physician has talked about psychological help in the past and that from her understanding ("I even thought") he had promised to arrange something (lines 12-13). Thereby, the patient treats the PN's suggestion as one in which she plays a passive rather than an active role. In other words, while the PN's proposal could have been taken up by the patient as requiring active participation, the patient treats it as a proposal. Hence, PNs make suggestions in which they position patients as service recipients and patients tend to go along with this role division. 


\section{2 | Declining help services}

In the 16 action planning episodes, PNs' action suggestions of using help services are generally not accepted by the patient. In extract 3 , from the same consultation as extract 2, the PN accepts the resistance and moves on to another topic, thus abandoning the action planning activity. Prior to extract 3, the PN further explored the patient's willingness to accept psychological help, which the patient assessed as "really very difficult" (data not shown).

\section{Extract 3}

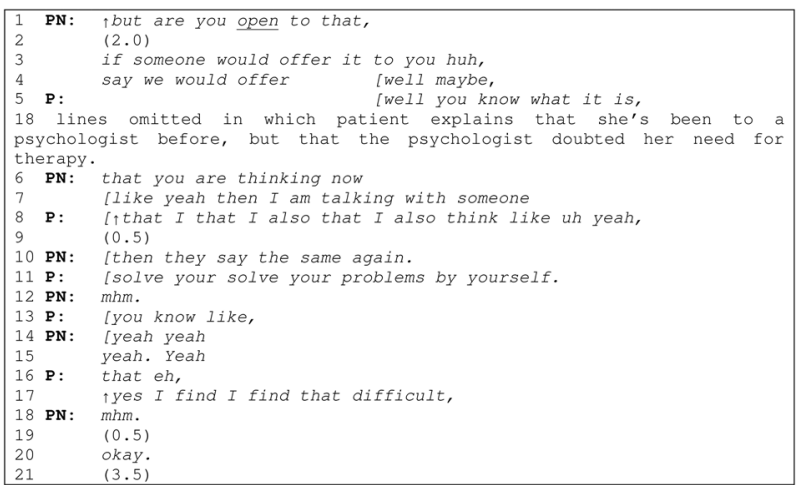

Initially, the PN uses a yes/no interrogative that questions the patient's openness toward help (line 1). This makes confirmation from the patient relevant (Raymond, 2003) and would constitute the basis for accepting psychological help. However, the patient remains silent (line 2) and thus displays resistance (Kinnell \& Maynard, 1996), upon which the PN expands her turn. She now presents the patient with the hypothetical situation ("if" in line 3 and "say" in line 4) that this help would be offered to her. Hence, the PN explicitly positions the patient as a passive patient and the $\mathrm{PN}$ and the family physician as the help providers ("we," line 4). The patient interrupts the PN with a well-prefaced turn (line 5), signalling non-straightforwardness (Heritage, 2015). She presents her objection to psychological treatment (data not shown), which originated from a previous experience of a psychologist doubting her need for therapy. The PN now no longer pursues acceptance of help and formulates the reason for resistance in co-construction with the patient (lines 6-11). Subsequently, the patient elicits explicit agreement ("you know like," line 13), which the PN provides (lines 14 and 15), although she does not initiate closing of the topic yet. It takes the patient to rephrase her resistance (lines 16-17) for the PN to accept the rejection of psychological help and close the topic ("okay," line 20) (Schegloff \& Sacks, 1973). Hence, the discussion of potential actions to solve the patient's depressed feelings is closed.

\subsection{Problems as the basis for action planning}

In some cases, PNs pursue patients' acceptance of available services. One way of doing this is to emphasize the problem status of the current situation. Thus, rather than exploring a goal for which a certain action would be needed, the action is motivated by stressing a problem (cf. Heritags \& Sefi, 1992). In the next example (extract 4), the service in question is a transportation service called "Mobicar" (patient code 3). The PN's visit was requested by the family physician and physiotherapist, who were worried about the patient's lack of mobility and social contacts. The PN and the patient have known each other for several years. In previous home visits the PN and the patient had discussed several possible solutions to the patient's problems. One solution to the patient's mobility problems was the Mobicar (a transportation service for elderly people). Prior to extract 4 , the patient explained that she had not used the Mobicar during the past months. The PN initiates the sequence with a version of the problem to which the Mobicar would work as a solution (lines 1-9).

\section{Extract 4}

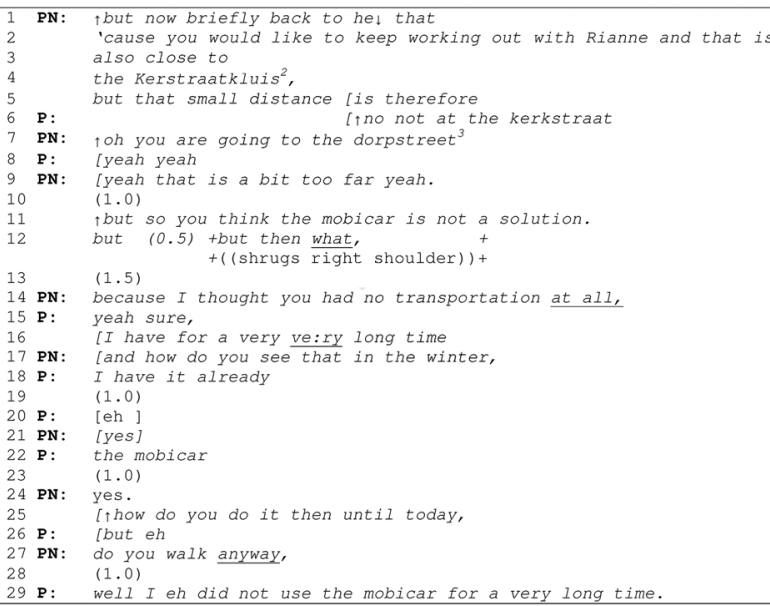

This fragment starts with the PN re-opening the topic of the Mobicar (line 1) using the initial "but" as a device for topic resumption (Mazeland $\&$ Huiskes, 2001). She sketches a specific situation for the patient in which immobility might be a problem for her (lines 2-4 and 9), which works toward an entry in advice giving (Heritags \& Sefi, 1992). The problem status is marked by "a bit too far" (line 9), which requires a solution. Agreement from the patient seems relevant here, but this is not provided (pause in line 10). Then, the PN formulates the patient's earlier rejection of the Mobicar as the solution to the problem (line 11). The lexical item "solution" is salient here, entailing the patient has a problem that needs a remedy. The PN continues asking "but (0.5) but then what" (line 12), implying there is no alternative. The patient, however, does not respond (line 13). Then, the PN goes on to argue for the need for a solution ("because," line 14), by enhancing the problem status ("no transportation at all") (Pomerantz, 1986). In other words, the PN pursues acceptance of the Mobicar service. Now the patient responds immediately (no pause) with a denial, claiming she has had the Mobicar for "a very ve:ry long time" (lines 15-16). The PN only responds to this minimally and uses other turns to emphasize aspects of the problem (what to do in winter, line 17; how the patient currently gets there, on foot or otherwise, lines 25 and 27). In sum, this example shows that PNs may pursue acceptance of available services by stressing the problem status of the situation. This strategy constrains the discussion of actions in response to a problem rather than actions toward a goal. 


\subsection{From passive patient to active agent}

The last extract shows an alteration from the PN in discussing actions. The following fragment is taken from the same consultation as extract 1 (patient code 1). Prior to extract 5 , the patient had explained that he would like to meet someone to spend time with.

\section{Extract 5}

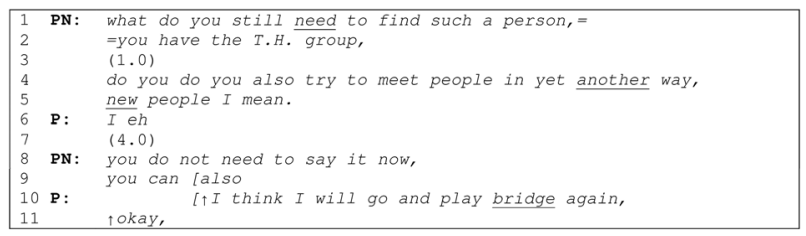

Initially, the PN phrases the question with the patient in subject position to the verb "need" (line 1), as in extract 1 . Note however, that the suggestion is phrased as a need toward a goal ("to find such a person" line 1), rather than as a solution to a problem. Even more exceptional in our data is that after a short pause (line 3), the PN self-repairs the question to "do you do you also try" (lines 4-5), which positions the patient as an active participant. Although the patient immediately starts a response after the PN's explanation of "new people," he breaks off his turn and remains silent (line 7). The PN manages the observable lack of an answer by excusing him (lines 8-9), but the patient interrupts her, using rising intonation and reports a plan for future action (playing bridge again, line 10). The PN acknowledges and positively evaluates this plan in response ("^okay," line 11). In conclusion, the design of the PN's questions invokes first a passive but then an active role for the patient. The latter question elicited an answer consisting of an action requiring active involvement of the patient rather than the acceptance of a service.

\section{4 | DISCUSSION}

This study aimed to gain more insight into how practice nurses set goals and agree on action plans with elderly people during home visits. However, although practice nurses planned to set goals together with their patients, goal setting in the strict sense was not observable and action planning was restricted to proposing the use of certain services. Practice nurses did not ask questions about what a patient wanted to change or achieve (goal-setting) and they did not collaboratively agree on a course of action with the patient (action-planning). The action planning that we identified consisted of nurses proposing the use of services to patients, which was frequently resisted. Moreover, the action planning was overwhelmingly grounded in or motivated by a current problem rather than by working toward a goal. Alternative questions or inviting the patient to phrase his/her own ideas for solutions were rare (one episode). Thus, practice nurses treated patients as passive agents (persons who are not capable of actively engaging in solving the problem in question) rather than as active agents (persons who are capable of actively engaging in solving the problem in question). Patients' contribution to the interaction merely involved responding to the solutions suggested by the practice nurse. When patients rejected or resisted the nurse's suggestions, the latter did not explore the reasons for resistance and the action planning came to an end.

There are several explanations for our findings, which can be divided into factors related to the practice nurse, the patient and the relationship between the patient and the nurse.

With regard to the practice nurse, it is possible that Dutch primary care nurses interpret the concepts of goal setting and action planning differently than the way goal setting/action planning is described in the literature. Suggesting the use of assistive services might be regarded as goal setting/action planning by nurses, yet when solutions are proposed to patients, the questions of "why" a certain behavior/solution is personally relevant, "what" the patient wants to reach and "how" the patient wants to reach that are not answered. Thereby, the patient might not be sufficiently motivated to carry out the action (Bodenheimer et al., 2005; Locke \& Latham, 2006). Moreover, it might be possible that nurses were uncertain about the patient's capabilities for setting goals and formulating their own action plans. In a process evaluation study of a selfmanagement program, Kennedy et al. (2014) showed that practice nurses were skeptical about patients' ability to set their own goals and action plans (Kennedy et al., 2014). The tendency to propose solutions to the patient, instead of asking the patient for goals or action plans, was also found in earlier conversation analytic studies of physiotherapist sessions (Parry, 2004; Schoeb, 2009). One explanation offered was that physiotherapists had doubts about the patient's potential for progress (Parry, 2004).

With regard to patient factors, patients' passive role in action planning might be explained by patients being accustomed to a more medical approach by their nurse. Although practice nurses working in Dutch elderly care are taught to approach their patients from an integral, holistic perspective, and to discuss problems on the emotional, or social level, it might be possible that patients do not expect practice nurses to talk about solutions for psychosocial problems or everyday life situations (Heiligers et al., 2012). In addition, it has been emphasized that not all patients are motivated, able and/or ready to take an active role in collaborative decision making regarding goals and actions (Joseph-Williams, Edwards, \& Elwyn, 2014; Levinson, Audiey, Kuby, \& Thisted, 2005). Patients in different phases of their behavioral change process might require different communication approaches for goal setting and action planning (Jones et al., 2003; Keefe et al., 2000).

Patient alignment with being cast in a passive role could also be related to an asymmetry between patients and nurses. Conversation analytic research has shown that limited patient participation and the asymmetry between the professional and the patient are not imposed only by professionals, but that both parties contribute to this asymmetry through their communicative actions (Maynard, 1991; Pilnick, 1998). Patients might refrain from suggesting their own solutions because they see it as the territory of the expert and because it would undermine the ground for seeking help (Heath, 1992; Parry, 2004). The asymmetry between the patient and the professional might 
also be grounded in a lack of trust between the patient and the practice nurse. It has been claimed that trust is a precondition for effectively setting personally relevant goals and action plans with patients (Entwistle, 2004). However, in all but one case in our study, the practice nurse and the patient did not have a long-lasting relationship and there was probably not a high extent of trust between them. Moreover, we had the impression that in some cases there was a lack of a shared view regarding the patient's problem. Patients did not request a home visit themselves; home visits were initiated by the family physician. The nurses knew the family physicians' perspective on the patient's problem, but did not frequently explore the patient's perspective in depth. Yet, goal setting/action planning should start with a thorough exploration of the patient's needs and problems (Bodenheimer et al., 2005; Scobbie et al., 2011). Only if the patient's perspective on his/her current and desired situation is fully explored can personal goals be set. Only if goals are set can action plans can be agreed upon (Scobbie et al., 2011).

To our knowledge, our study is the first to examine how practice nurses actually carry out goal setting and action planning with patients. The study provides insights into the communicative practices and the communicational difficulties nurses face. The strength of the analysis is that it is based on actual interaction rather than on accounts. A conversation analytic approach might support professionals in analysing their own way of working (Parry, 2004). A limitation of our study is that we did not study goal setting/action planning practices conducted by other health care professionals working in elderly care, nor did we study home visits that were requested by the patient rather than instigated by the family physician or nurse. Future studies should use a larger data set to verify the patterns we found and to explore potential alternative practices of goal setting and action planning for nurses, patients, and other health care professionals.

Another critical note can be made with regard to the cross-sectional character of our study. By means of observations, we focused our analysis on the practice nurses' and patients interactions at a specific time and place. However, goal setting and action planning is a continuous process, and goals and action plans develop over time. Applying a more longitudinal conversation analytic study might capture the process of goal setting/action planning in a more comprehensive manner.

\section{5 | CONCLUSION}

In our data, explicit goal setting was not observable. However, we found action planning episodes in which actions to solve patients problems were suggested by the nurses. These suggestions were overwhelmingly oriented in favor of professional help and/or assisting services. The practice nurses treated the patients as passive patients and organizations as help providers. Patients tended to align with the passive role, and frequently displayed resistance to the nurses' suggestions. Our study raises awareness of the crucial role of communicative practices and use of language in approaching patients as active problem solvers in the service of increased self-management.

\section{6 | PRACTICE IMPLICATIONS}

Our findings increase overall awareness of the crucial role of language and communication in encouraging patients to set goals and make action plans. Although a considerable body of literature exists on the practice nurses' role in goal setting/action planning, there are few studies that actually show and highlight the complexity of this specific type of communication with patients. Our findings are therefore useful for developing interventions, focusing on goal setting and action planning. Moreover, educational programs for practice nurses should pay more attention to equipping practice nurses with sufficient skills for goal setting and action planning with patients.

\section{ACKNOWLEDGMENTS}

We would like to thank the participants of the ARTTIS data session in Utrecht, December 2016. This study was funded by Stichting Innovatie Alliantie (PRO-3-36) and the Zuyd University of Applied Sciences, Heerlen, the Netherlands.

\section{CONFLICTS OF INTEREST}

The authors declare no conflicts of interest.

\section{ENDNOTES}

${ }^{1}$ The incorrect grammar in the translation reflects incorrect grammar in the Dutch original.

${ }^{2}$ First location of the physical therapy practice.

${ }^{3}$ Second location of the physical therapy practice.

\section{ORCID}

Stephanie A. Lenzen iD http://orcid.org/0000-0002-7803-8506

\section{REFERENCES}

Ahmad Al-Harahsheh, A. M. (2015). A conversation analysis of self-initiated repair structures in Jordanian spoken Arabic. Discourse Studies, 17, 397-314. https://doi.org/10.1177/1461445615578898.

Atkinson, J. M., \& Heritage, J. (1984). Structures of Social Action: Studies in Conversation Analysis. Cambridge: Cambridge University Press.

Bodenheimer, T., MacGregor, K., \& Sharifi, C. (2005). Helping Patients Manage their Chronic Conditions. California: California Health-Care Foundation.

Bodenheimer, T., \& Grumbach, K., (2007). Self-management support for people with chronic illness. In J. F. Shanahan, \& R. Brown (Eds.), Improving Primary Care - Strategies and Tools for a Better Practice (pp. 79-94). New York: The McGraw-Hill Companies.

Bodenheimer, T., \& Handley, M. A. (2009). Goal-setting for behavior change in primary care: an exploration and status report. Patient Education and Counselling, 76, 174-180. https://doi.org/10.1016/j.pec.2009.06.001.

Drew, P., Chatwin, J., \& Collins, S. (2001). Conversation analysis: a method for research into interactions between patients and health-care professionals. Health Expectations, 4, 58-70. 
Edwards, D., \& Fasulo, A. (2006). "To be honest": sequential uses of honesty phrases in talk-in-interaction. Research on Language and Social Interaction, 39, 343-376. https://doi.org/10.1207/s15327973rlsi3904_1.

Embrey, N. (2006). A concept analysis of self-management in long-term conditions. British Journal of Neuroscience Nursing, 2, 507-513. https:// doi.org/10.12968/bjnn.2006.2.10.22535.

Entwistle, V. (2004). Editorial. Trust and shared decision making: an emerging research agenda. Health Expectations, 7, 271-271.

Heath, C. (1986). Body movement and speech in medical interaction Cambridge: Cambridge University Press.

Heath, C., (1992). The delivery and reception of diagnosis in the general-practice consultation. In P. Drew, \& J. Heritage (Eds.), Talk at work - Interaction in Institutional Settings (pp. 235-267). Cambridge: Cambridge University Press.

Heiligers, P.J.M., Noordman, J., Korevaar, J.C., Dorsman, S., Hinstman, L., van Dulmen, A.M., \& de Bakker, D.H. (2012). Kennisvraag: Praktijkondersteuners in de huisartspraktijk ( $\mathrm{POH}$ 's). Klaar voor de toekomst? [Knowledge base: Practice nurses in family medicine. Ready voor the future?]. Utrecht: Netherlands Institute for Health Services Research (NIVEL).

Heritage, J. (2015). Well-prefaced turns in English conversation: a conversation analytic perspective. Journal of Pragmatics, 88, 88-104. https://doi.org/10.1016/j.pragma.2015.08.008.

Heritage, J., \& Clayman, S., (2010). Talk in action: interactions, identities, and institutions. New York: Willey Blackwell.

Heritags, J., \& Sefi, S., (1992). Dilemmas of advice: Aspects of the delivery and reception of advice in interactions between health visitors and first time mothers. In P. Drew, \& J. Heritage (Eds.), Talk at work: Interaction in Institutional Settings (pp. 359-419). Cambridge: Cambridge University Press.

Jefferson, G., (2004). Glossary of transcript symbols with an introduction. In G. Lerner (Ed.), Conversation Analysis: Studies from the First Generation (pp. 13-31). Amsterdam/Philadelphia: John Benjamins Publishing, https://doi.org/10.1075/pbns.125.02jef

Jones, H., Edwards, L., Vallis, T. M., Ruggiero, L., Rossi, S. R., Rossi, J. S., .. . Zinman, B. (2003). Changes in diabetes self-care behaviors make a difference in glycemic control. Diabetes Care, 26, 732-737. https://doi. org/10.2337/diacare.26.3.732.

Joseph-Williams, N., Edwards, A., \& Elwyn, G. (2014). Knowledge is not power for patients: A systematic review and thematic synthesis of patient-reported barriers and facilitators to shared decision making. Patient Education and Counselling, 94, 291-309.

Keefe, F. J., Lefebvre, J. C., Kerns, R. D., Rosenberg, R., Beaupre, P., Prochaska, J., .. . Caldwell, D. S. (2000). Understanding the adoption of arthritis self-management: stages of change profiles among arthritis patients. Pain, 87, 303-313. https://doi.org/10.1016/S0304-3959(00) 00294-3.

Kennedy, A., Rogers, A., Bowen, R., Lee, V., Blakeman, T., Gardner, C., .. Chew-Graham, C. (2014). Implementing, embedding and integrating self-management support tools for people with long-term conditions in primary care nursing: a qualitative study. International Journal of Nursing Studies, 51, 1103-1113. https://doi.org/10.1016/j.ijnurstu.2013. 11.008.

Kinnell, A. M. K., \& Maynard, D. W. (1996). The delivery and receipt of safer sex advise in pretest counselling sessions for HIV and AIDS. Journal of contemporary ethnography, 24, 405-437.

Laurent, M., Reeves, D., Hermens, R., Braspenning, J., Grol, R., \& Sibbald, B. (2005). Substitution of doctors by nurses in primary care. Cochrane Database Systematic Reviews, 18, CD001271. https://doi.org/10.1186/ 1472-6963-14-214.

Lenzen, S. A., Daniëls, R., van Bokhoven, M. A., van der Weijden, T., \& Beurskens, A. (2015). Setting goals in chronic care: shared decision making as self-management support by the family physician. European Journal of General Practice, 21, 138-144. https://doi.org/10.3109/ 13814788.2014.973844.
Levinson, W., Audiey, K., Kuby, A., \& Thisted, R. A. (2005). Not all patients want to participate in decision making: a national study of public preferences. Journal of General Internal Medicine, 20, 531-535. https:// doi.org/10.1111/j.1525-1497.2005.04101.x.

Locke, E. A., \& Latham, G. P. (2006). New directions in goal-setting theory. Current directions in psychological science, 15, 265-268. https://doi.org/ 10.1111/j.1467-8721.2006.00449.x.

Lorig, K. (2006). Action planning: a call to action. The Journal of the American Board of Family Medicine, 19, 324-325. https://doi.org/10.3122/ jabfm.19.3.324.

MacDonald, W., Rogers, A., Blakeman, T., \& Bower, P. (2008). Practice nurses and the facilitation of self-management in primary care. Journal of Advanced Nursing, 62, 191-199. https://doi.org/10.1111/j.13652648.2007.04585.x.

Maynard, D. J. (1991). Interaction and asymmetry in clinical discourse. American Journal of Sociology, 97, 448-495. https://doi.org/10.1086/229785.

Mazeland, H., \& Huiskes, M., (2001). Dutch "but" as a sequential conjunction: its use as a resumption marker. In M. Selting, \& E. Couper-Kuhlen (Eds.), Studies in Interactional Linguistics (pp. 141-169). Amsterdam/Philadelphia: John Benjamins Publishing.

Oettingen, G., \& Gollwitzer, P. M., (2010). Strategies of setting and implementing goals: mental contrasting and implementation intentions. In J. E. Maddux, \& J. P. Tangney (Eds.), Social Psychological Foundations of Clinical Psychology (pp. 114-135). New York: Guilford Press.

Parry, R. H. (2004). Communication during goal-setting in physiotherapy treatment sessions. Clinical Rehabilitation, 18, 668-682. https://doi. org/10.1191/0269215504cr745oa.

Peräkylä, A., (2004). Conversation analysis. In C. Seale, D. Silverman, J. Gubrium, \& G. Gobo (Eds.), Qualitative Research Practice (pp. 165-179). London: Sage.

Peräkylä, A. (1997). Conversation analysis: a new model of research in doctor-patient communication. Journal of the Royal Society of Medicine, 90, 205-208.

Pilnick, A. (1998). Why didn't you say just that? Dealing with issues of asymmetry, knowledge and competence in the pharmacist/client encounter. Sociology of Health \& Illness, 20, 29-51. https://doi.org/ 10.1111/1467-9566.00079.

Pomerantz, A. (1986). Extreme case formulations: a way of legitimizing claims. Human Studies, 9, 219-229.

Raymond, G. (2003). Grammar and social organization: yes/no interrogatives and the structure of responding. American Sociological Review, 68, 939-967.

Robinson, J. (1998). Getting down to business: talk, gaze and body orientation during opening of doctor-patient consultations. Human Communication Research, 25, 97-123.

Schegloff, E. A., \& Sacks, H. (1973). Opening up closing. Semiotica, 4, 69-99.

Schoeb, V. (2009). The goal is to be more flexible - detailed analysis of goal setting in physiotherapy using a conversation analytic approach. Manual Therapy, 14, 665-670. https://doi.org/10.1016/j.math.2009.02.004.

Schulman-Green, D. J., Naik, A. D., Bradley, E. H., McCorkle, R., \& Bogardus, S. T. (2006). Goal setting as a shared decision making strategy among clinicians and their older patients. Patient Education and Counseling, 63, 145-151. https://doi.org/10.1016/j.pec.2005.09.010.

Scobbie, L., Dixon, D., \& Wyke, S. (2011). Goal-setting and action planning in the rehabilitation setting: development of a theoretically informed practice framework. Clinical Rehabilitation, 25, 468-482. https://doi. org/10.1177/0269215510389198.

Ten Have, P. (2007). Doing conversation analysis. A practical guide. London: Sage.

Van Dijk-de Vries, A. (2015). Towards integrated nurse-led self-management support in routine diabetes care (Doctoral dissertation). Retrieved from Maastricht University.

van Dillen, S. M., Noordman, J., van Dulmen, S., \& Hiddink, G. J. (2015). Setting goal and implementation intentions in consultations between practice nurses and patients with overweight or obesity in general 
practice. Public Health Nutrition, 18, 3051-3059. https://doi.org/ 10.1017/S1368980015000075.

Vermunt, N. P. C. A., Harmsen, M., Westert, G. P., Rikkert, M. G. M. O., \& Faber, M. J. (2017). Collaborative goal setting with elderly patients with chronic disease or multimorbidity: a systematic review. BMC Geriatrics, 17, 167. https:// doi:10.1186/s12877-017-0534-0.

Wagner, E. H., Bennett, S. M., Austin, B. T., Greene, S. M., Schaefer, J. K., \& Von Korff, M. (2005). Finding common grounds: patient-centeredness and evidence based chronic illness care. Journal of Alternative Complementary Medicine, 11, 7-15. https://doi.org/10.1089/acm. 2005.11.s-7.

Willard-Grace, R., Chen, E. H., Hessler, D., DeVore, D., Prado, C., Bodenheimer, T., \& Thom, D. H. (2015). Health coaching by medical assistants to improve control of diabetes, hypertension, and hyperlipidemia in low-income patients: a randomized controlled trial. The Annals of Family Medicine, 13, 130-138. https://doi.org/10.1370/afm.1768.

\section{SUPPORTING INFORMATION}

Additional supporting information may be found online in the Supporting Information section at the end of the article.

How to cite this article: Lenzen SA, Stommel W, Daniëls R, van Bokhoven MA, van der Weijden T, Beurskens A. Ascribing patients a passive role: Conversation analysis of practice nurses' and patients' goal setting and action planning talk. Res Nurs Health. 2018;41:389-397.

https://doi.org/10.1002/nur.21883 